\title{
Casos Prácticos de Organizaciones de Economía Social para la Docencia en Dirección y Gestión de Empresas
}

\author{
Ignacio Bretos \\ Isabel Saz-Gil \\ Millán Díaz-Foncea \\ Carmen Marcuello \\ Alejandro Pascual \\ Cristina Sánchez-Herrando \\ Clara Sarasa
}


Autores *

(c) Ignacio Bretos, Isabel Saz-Gil, Millán Díaz-Foncea, Carmen Marcuello, Alejandro Pascual, Cristina Sánchez-Herrando y Clara Sarasa.

Universidad de Zaragoza

* Todos los autores han contribuido de manera equitativa en la investigación.

\section{Editado y publicado por:}

Cátedra Cooperativas y Economía Social, Caja Rural de Teruel.

Facultad de Economía y Empresa

Universidad de Zaragoza.

Gran Vía 2, 50005, Zaragoza, España.

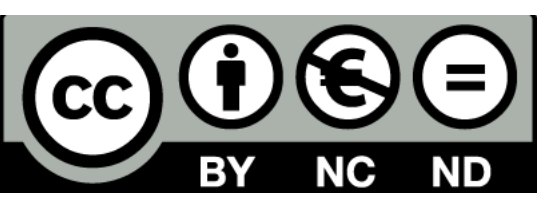
Recurso electrónico
ISBN: 978-84-946082-9-2
DOI: $10.26754 / u z .978-84-946082-9-2$ 
Financiado por:
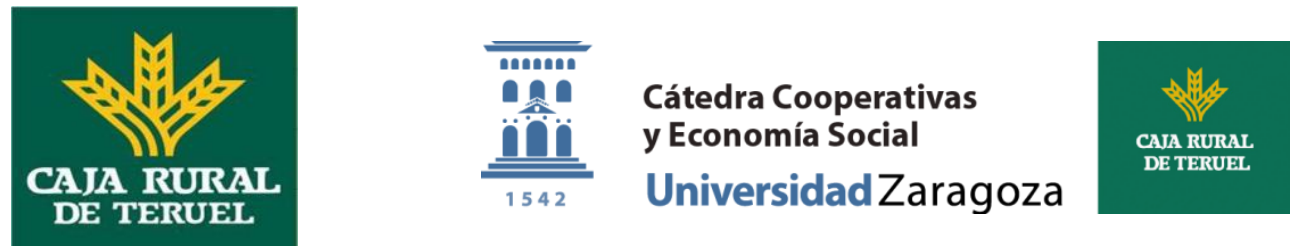

Caja Rural de Teruel

Con la colaboración de:

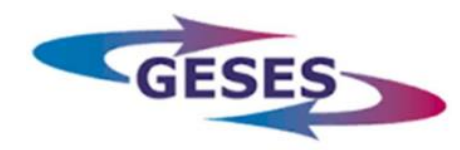

UNIVERSIDAD DE ZARAGOZA

Grupo de Estudios Sociales y

Económicos del Tercer Sector

GESES-Grupo de Estudios Sociales y Económicos del Tercer Sector, Universidad de Zaragoza. Financiado por el Gobierno de Aragón (Referencia S28_17R) y cofinanciado con FEDER 2014-2020 "Construyendo Europa desde Aragón".

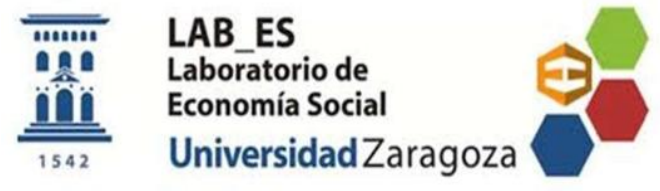

LAB_ES, Laboratorio de Economía Social, Facultad de Economía y Empresa de la Universidad de Zaragoza.

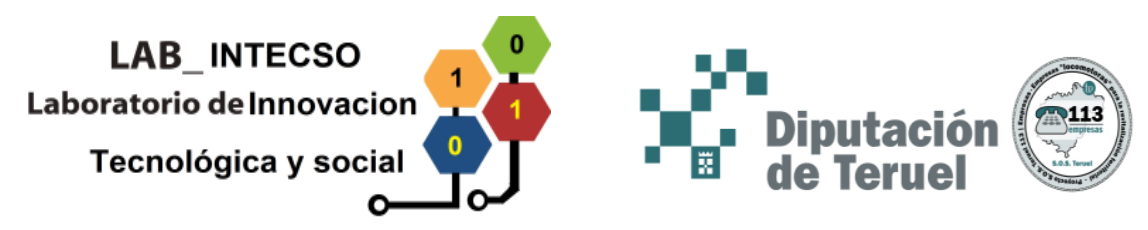

LAB_INTECSO, Laboratorio de Innovación Tecnológica y Social, Facultad de Ciencias Sociales y Humanas de Teruel. 


\section{Índice general de contenidos}

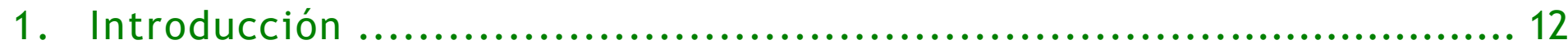

2. Casos de Empresas de Economía Social de Aragón ................... 16

3. Casos de Empresas de Economía Social de España ......................32

4. Casos de Empresas de Economía Social de Iberoamérica .............. 41

5. Casos de Empresas de Economía Social Multinacionales ................46

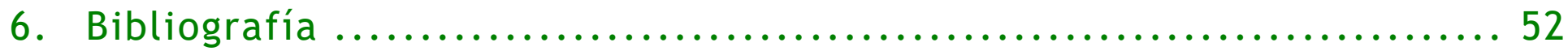




\section{Caja Rural de Teruel}

Caja Rural de Teruel (https://www.ruralvia.com/teruel/) es una cooperativa de crédito española. Forma parte de la Asociación Española de Cajas Rurales y de la Unión Nacional de Cooperativas de Crédito. El origen de la Caja se remonta al año 1920, cuando se crea la Federación Turolense de Sindicatos Agrícolas Católicos.

Caja Rural de Teruel está además integrada en el Grupo Caja Rural, uno de los principales grupos bancarios que operan en España al contar con 2.300 oficinas y más de 8.000 empleados. La gran solidez financiera y patrimonial del Grupo se refleja en los Activos Totales del Grupo de 59.394 millones de euros y unos Fondos Propios de 4.783 millones de euros.

El marco institucional que representa el Grupo Caja Rural, así como la estructura empresarial que ha surgido en torno a ella, confirma la consolidación del proceso de concentración reciente de la banca cooperativa española. El sistema de integración adoptado por el Grupo sigue un modelo de banca federada, que permite salvaguardar la autonomía de las Cajas Rurales Asociadas sin renunciar al requisito indispensable de operatividad bancaria y eficiencia empresarial. Las Cajas Rurales del Grupo tienen, por tanto, un campo de actuación definido para desempeñar su papel de forma diferenciada pero no aislada, ya que la cooperación permite acceder a ámbitos más amplios y a la vez les permite mantener intacta la vinculación con su ámbito territorial. 
Caja Rural de Teruel es una organización ampliamente reconocida dentro y fuera de Aragón, tanto por su actividad económica fuertemente enraizada en el territorio como por su relevante labor social, estrechamente vinculada a los principios y valores cooperativos. A 31 de diciembre de 2017, la Caja se estructuraba en 78 oficinas (72 en Teruel, 3 en Zaragoza, 2 en Tarragona y 1 en Castellón) y englobaba una plantilla total de 186 empleados a tiempo completo, contando además con 21.000 socios.

Asimismo, Caja Rural de Teruel aporta todos los años el 15\% de sus beneficios a la dotación del Fondo de Educación, Promoción y Obras Sociales, destinado al patrocinio y el apoyo de distintas actividades de carácter social, cultural, formativo y de promoción, siempre dentro de su ámbito de actuación.

En este sentido, la Caja tiene suscritos alrededor de 30 convenios sectoriales y territoriales con colectivos profesionales de todo tipo. Participa en el capital de más de 20 empresas y apoya más de 800 actuaciones al año en colaboración con diferentes iniciativas sociales, culturales, deportivas o de formación, así como en fundaciones como la Universidad de Teruel, la Fundación Bodas de Isabel o la Fundación Buñuel. Asimismo, apoya las 20 ferias agrícolas de la provincia de Teruel y las cuatro Denominaciones de Origen (jamón, ternasco, aceite y melocotón). 
La Cátedra Cooperativas y Economía Social (http://catedraeconomiasocial.unizar.es/) nace en abril de 2016, fruto de la colaboración entre Caja Rural de Teruel y la Universidad de Zaragoza, con el objetivo principal de contribuir a la generación de conocimiento en el ámbito del cooperativismo y la Economía Social. De manera más concreta, la Cátedra persigue tres objetivos específicos:

> Fomentar el conocimiento sobre las cooperativas y las organizaciones de la Economía Social en el ámbito de la comunidad universitaria.

> Promover la iniciativa emprendedora en el ámbito de la comunidad universitaria y en colaboración con las instituciones del sector de la Economía Social.

> Estimular la investigación sobre la realidad, problemática y perspectivas de las cooperativas y la Economía Social.

Para alcanzar dichos objetivos, la Cátedra lleva a cabo diversos tipos de actividades, entre las que destacan las siguientes:

- Elaboración de un informe anual sobre la situación de las cooperativas y la Economía Social en Aragón así como informes sectoriales que se consideren necesarios.

- Colaboración y asesoramiento en la elaboración de otros informes sobre la Economía Social aragonesa. Por ejemplo, en 2017, la Cátedra colaboró con el Laboratorio de Economía Social de la Facultad de Economía y Empresa participando en el informe "El Emprendedor Cooperativo en Zaragoza".

- Dotación de becas para estudiantes que realicen estudios en materia de Economía Social, como por ejemplo el posgrado Experto Universitario en Economía Social (EUES). 
- Dotación de becas para estudiantes que realicen estudios en materia de Economía Social, como por ejemplo el posgrado Experto Universitario en Economía Social (EUES).

- Organización de cursos y seminarios, dirigidos tanto a la comunidad científica como al entorno empresarial en colaboración con el EUES.

- Realización de actividades que permitan la transferencia del conocimiento de los profesionales externos a los estudiantes.

- Apoyo y difusión para la realización de prácticas de estudiantes en el ámbito de las cooperativas y la Economía Social.

- Colaboración con la asignatura de Dirección de Entidades de Economía Social del grado en ADE y apoyo a proyecto de Laboratorio de Economía Social en la Facultad Economía y Empresa de la Universidad de Zaragoza.

- Apoyo a la elaboración de tesis doctorales, proyectos fin de grado y trabajos fin de master dirigidos al estudio de la Economía Social.

- Financiación de proyectos de investigación dirigidos al estudio de las cooperativas y la Economía social.

- Concesión de premios.

En este contexto, la Cátedra colabora estrechamente con diversas instituciones y plataformas de la Economía Social como CEPES-Aragón, el Posgrado EUES (Experto Universitario en Economía Social) de la Universidad de Zaragoza, el Grupo de Investigación GESES (Grupo de Estudios Sociales y Económicos del Tercer Sector), el GIDID (Grupo Interdisciplinar de Innovación Docente de la Universidad de Zaragoza), el Laboratorio de Economía Social (LAB_ES) y la Red ENUIES. 


\section{Equipo de trabajo}

- Directora: Carmen Marcuello Servós, Universidad de Zaragoza

- Subdirectora: Isabel Saz Gil, Universidad de Zaragoza

- Coordinador: Ignacio Bretos Fernández, Universidad de Zaragoza

\section{Comisión Mixta:}

- José Antonio Pérez Cebrián, Director General Caja Rural de Teruel

- Javier Cánovas Murcia, Director Oficina de Zaragoza, Caja Rural de Teruel

- Francisco Lara Hernández, Subdirector Área de Negocio, Caja Rural de Teruel

- Yolanda Polo, Vicerrectora de Cultura y Proyección Social

- Alexia Sanz, Vicerrectora del Campus Teruel

- José Mariano Moneva, Decano Facultad Economía y Empresa

\section{Equipo Asesor:}

- Patricia Almaguer Kalixto: Dpto. Psicología y Sociología

- Cristina Bernad Mocarte: Dpto. Dirección y Organización de Empresas

- Millán Díaz Foncea: Dpto. Dirección y Organización de Empresas

- Pedro J. Escriche Bueno: Dpto. Psicología y Sociología

- Chaime Marcuello Servós: Dpto. Psicología y Sociología

- Alejandro Pascual Fernández: Laboratorio de Economía Social (LAB_ES)

- Pablo Pérez Benedí: ITAINNOVA, Instituto Tecnológico de Aragón

- Francisco Javier Pérez Sanz: Dpto. Dirección y Organización de Empresas

- Cristina Sánchez Herrando: REAS-Aragón, Red de Economía Alternativa y Solidaria

- Clara Sarasa Aznar: Departamento de Estructura e Historia Económica y Economía Pública Anabel Zardoya Alegría: Dpto. Contabilidad y Finanzas 


\section{Laboratorio de Economía Social (LAB_ES)}

El LAB_ES, Laboratorio de Economía Social (https://labes-unizar.es/) se pone en marcha a principios del año 2017 gracias al convenio de colaboración firmado entre el Ayuntamiento de Zaragoza (a través del Instituto Municipal de Empleo y Fomento Empresarial, Zaragoza Dinámica) y la Universidad de Zaragoza, consistente en realizar actuaciones relacionadas con la Economía Social.

El Laboratorio se concibe como un espacio para que la comunidad universitaria tenga la oportunidad de experimentar con la Economía Social, esto es, un lugar donde el alumnado, el personal docente e investigador (PDI) y el personal de administración y servicios (PAS) de la Universidad de Zaragoza pueda practicar con proyectos económicos basados en los principios de la Economía Social, tales como la participación, apoyo mutuo, solidaridad y compromiso con el entorno, y en contacto directo con la realidad empresarial y asociativa de este sector.

El LAB_ES pretende erigirse como un punto de referencia para el desarrollo de proyectos socialmente responsables, ecológicamente sostenibles y económicamente viables, que permitan al alumnado aplicar de forma práctica los conocimientos adquiridos en la carrera, conociendo el entorno social y económico desde un punto de vista diferente. Asimismo, el LAB_ES se establece como un espacio para que el PDI y el PAS puedan desarrollar prácticas colectivas innovadoras y diseñar nuevas metodologías docentes vinculadas a la transferencia de conocimiento y el trabajo cercano al alumnado y las entidades sociales de la ciudad. 
Los proyectos e ideas a desarrollar en el LAB_ES deben respetar las siguientes premisas básicas:

- Se promuevan desde los principios y valores de la economía social

- Se enfoquen a la puesta en marcha de proyectos reales

- Apuesten por la Transferencia de Conocimiento

- Generen innovación social

- Obtengan un impacto social positivo para la sociedad

El LAB_ES agrupa sus actividades y ejes de trabajo en torno a diversos espacios que pretenden conformar una amplia oferta para la experimentación aplicada, el pensamiento crítico y la generación de innovación social, con el fin de investigar y proponer iniciativas económicas transformadoras. Estos son:

(i) El Espacio de trabajo colectivo, concebido para desarrollar proyectos propios o colaborar en otros proyectos de entidades de Economía Social.

(ii) El Espacio de Participación de la Comunidad Universitaria, que pretende fomentar el empoderamiento de la comunidad universitaria mediante proyectos de Economía Social, realizar actividades basadas en la transferencia de conocimiento a la sociedad, e iniciar procesos para promover pautas de consumo responsables y respetuosos con el entorno y la sociedad.

(iii) El Espacio de Investigación Colectiva, que busca crear, promover y visibilizar recursos útiles para conocer y visibilizar la Economía Social a través de la investigación colectiva de diversos actores. 


\section{Introducción}




\section{Introducción}

Uno de los principales objetivos de la Cátedra Cooperativas y Economía Social Caja Rural de Teruel, de la Universidad de Zaragoza, consiste en el fomento del conocimiento sobre las cooperativas y las organizaciones de la Economía Social en el ámbito de la comunidad universitaria. Sin duda, una de las vías esenciales para lograrlo reside en promover una mayor inclusión y visibilidad de este tipo de organizaciones dentro de la docencia universitaria, con particular incidencia en las materias relacionadas con la economía y con la dirección y gestión de empresas.

En este marco, el documento presenta una colección de 32 casos prácticos breves de organizaciones entroncadas en el sector de la Economía Social con un doble objetivo. Por un lado, pretendemos difundir y visibilizar la labor de distintas empresas y organizaciones relevantes del sector que, desde enfoques, trayectorias y actividades diversas, contribuyen a transformar la realidad socio-económica de los territorios donde operan. Como parte de la Economía Social, estas organizaciones llevan a cabo sus actividades desde unas coordinadas alternativas a los modelos tradicionales de empresa, en tanto que se basan en principios como la primacía de las personas y del fin social sobre el capital, la independencia y autonomía en la gestión con respecto a los poderes públicos, la adhesión voluntaria y abierta, la gestión democrática por parte de los miembros, o la defensa y aplicación de los principios de solidaridad y responsabilidad.

Por otro lado, esperamos que los casos prácticos presentados puedan servir de referencia para la docencia no sólo en el ámbito específico de la economía social y solidaria, sino en disciplinas científicas más generales como la economía, la sociología y la dirección y gestión de empresas. 
Cada uno de los casos muestra la información esencial de empresas y organizaciones de la economía social de Aragón, España, Iberoamérica y multinacionales.

En concreto, se han recogido datos básicos sobre distintas variables como la fecha de creación, el número de empleos, socios y/o voluntarios, el sector de actividad y los servicios ofrecidos, hitos organizacionales y el número de organizaciones que integran (en el caso de grupos empresariales o de plataformas y redes). También se facilitan recursos electrónicos, como las páginas web institucionales, redes sociales o vídeos corporativos.

Finalmente, cabe señalar que esta publicación se ha elaborado en un marco de colaboración entre los miembros de un equipo investigador que formamos parte de una 0 varias redes de trabajo relacionadas con el ámbito de la Economía Social en la Universidad de Zaragoza, como son la Cátedra Cooperativas y Economía Social Caja Rural de Teruel, el grupo de investigación GESES (Grupo de Estudios Sociales y Económicos del Tercer Sector) y el Laboratorio de Economía Social (LAB_ES) de la Facultad de Economía y Empresa.

Nuestra intención es continuar con este proyecto en el futuro, incluyendo cada año un abanico distinto de empresas y entidades de la Economía Social. Para ello, será fundamental la participación de diferentes colaboradores que quieran sumarse al proyecto. 


\section{Listado casos Aragón}

ATADI

Caja Rural de Teruel

Cereales Teruel

Cooperativa Los Monegros

Fundación Rey Ardid

Fundación Picarral

Fundación Adunare

Grupo Arcoiris

Grupo Ars Alendi

Grupo Pastores

Mapiser

MESCoop

Musethica

San Juan Bautista Soc. Coop.

Iberoamérica

Cooperativa Integral Agrícola Mujeres 4pinos (Guatemala) Central de Cooperativas El Ceibo (Bolivia) Meri Henua Cooo (Chile) Unión Cooperativa Tosepan (México)

Tiebel S.Coop

\section{España}

Multinacionales

Coop57

Fundación Espriu

Koopera

La Borda Cooperativa

La Traviesa

Smartlb

Som Energia

Tasubinsa
Arla Foods

Co-op

Grupo Mondragón

Group Up Rabobank 


$$
\begin{array}{r}
\text { Casos de } \\
\text { Empresas de } \\
\text { Economía Social } \\
\text { Aragón }
\end{array}
$$


ATADI tiene como objetivo aportar los apoyos necesarios, para que cada persona con discapacidad intelectual o del desarrollo y su familia, puedan llevar a cabo su proyecto de vida, así como promover su inclusión, como ciudadano de pleno derecho en una sociedad justa y solidaria. Apuesta por la calidad. Entre los servicios ofrecidos: Básicos (Residencia, Centro Ocupacional, Centro de Día, Centro Especial de Empleo). Complementarios (comedor, transporte, servicio de modificación de conducta, servicio fisioterapia, servicio de psicomotricidad, servicio psicopedagógico, servicio de respiro, actividades físicodeportivas, actividades de ocio y tiempo libre).

La asociación ATADI es una entidad de acción social sin ánimo de lucro resultado de la unión de asociaciones y entidades integradas en ella. Tiene personalidad jurídica propia. Registrada en 2005 por el Departamento de Servicios Sociales y Familia del Gobierno de Aragón. En 2008, la Secretaría General Técnica, Subdirección general de Estudios y Relaciones Institucionales declaró a (ATADI), Entidad de Utilidad Pública en el registro de la Comunidad de Aragón.

Su ámbito de actuación se extiende a todo el territorio que comprende la Provincia de Teruel.

\section{http://www.atadi.es/}

https: / / www.youtube.com/watch?v=qLrKudiiX $\underline{0 c}$

Datos básicos:

- CEE ATADI Empleo: 35 trabajadores.

Residencia Estrella: 20 plazas, 2 de Respiro.

Vivienda Tutelada

- Andorra Sierra Arcos: 27 usuarios + 6 de CEE, 13 trabajadores

- Cuencas Mineras: 33 usuarios, 14 trabajadores.

Bajo Aragón y Bajo Martín: 28 usuarios + 10 de CEE, 10 trabajadores

- Comunidad de Teruel: 81 usuarios, 25 trabajadores

- Comarca del Jiloca y Sierra de Albarracín: 14 usuarios, 4 trabajadores.

- Bajo Aragón, Andorra Sierra de Arcos, Maestrazgo, Cuencas Mineras: 38 usuarios, 34 trabajadores.

- Maestrazgo: 13 usuarios, 10 trabajadores.

- Gúdar-Javalambre: 18 usuarios, 11 trabajadores.

- Albarracín: 10 usuarios, 2 trabajadores.

Matarraña: 7 usuarios, 2 trabajadores. 
- Caja Rural de Teruel cuenta con el sello de Responsabilidad Social de Aragón, que otorga la Diputación General de Aragón por medio del Instituto Aragonés de Fomento.

caja rúrat

DE TERUEL

\section{Caja Rural de Teruel}

Caja Rural de Teruel es una cooperativa de crédito y forma parte de la Asociación Española de Cajas Rurales y de la Unión Nacional de Cooperativas de Crédito. El origen de la Caja se remonta al año 1920. Caja Rural de Teruel está además integrada en el Grupo Caja Rural, uno de los principales grupos bancarios que operan en España

https://www.ruralvia.com/teru el/
- Participa en el capital de más de 20 empresas y apoya más de 800 actuaciones al año en colaboración con diferentes iniciativas sociales, culturales, deportivas o de formación

\section{Cifras 2017}

- la Caja se estructuraba en 78 oficinas (72 en Teruel, 3 en Zaragoza, 2 en Tarragona y 1 en Castellón) y englobaba una plantilla total de 186 empleados a tiempo completo, contando además con 21.000 socios. Asimismo, Caja Rural de Teruel aporta todos los años el $15 \%$ de sus beneficios a la dotación del Fondo de Educación, Promoción y Obras Sociales, destinado al patrocinio y el apoyo de distintas actividades de carácter social, cultural, formativo y de promoción, siempre dentro de su ámbito de actuación. 


\section{Cereales Teruel}

$\begin{array}{lcr}\text { Cereales } & \text { Teruel } & \begin{array}{r}\text { Sociedad } \\ \text { Cooperativa }\end{array} \\ \text { es un } & \text { grupo } \\ \text { sociedades. } & \text { Reconocida } & \text { como }\end{array}$
Agrupación de Productores Agrarios desde el año 1991. Marca de garantía de Producción Integrada de Aragón.

Operador de Producción Ecológica de Aragón.

Implicada en proyecto Harmony. Reconocida como Agrupación de Tratamiento Integrado Agricultura. en http://cerealesteruel.com/
- Cereales Teruel tiene por objetivo proporcionar alimentos de calidad. Generar empleo y vida en los pueblos. Por lo que es mantenedor del territorio.

- Es productor multiplicador de semillas de cereal y forrajeras. Comercializa inputs básicos: gasóleo y fertilizantes.

- Asesora en materia de condicionalidad y requisitos legales de gestión, a través de la Asociación para el Desarrollo Rural Integral Aragonés

\section{Datos básicos}

- Más de 2.500 socios agrupados en diez secciones que se ubican en distintos municipios del Alto Teruel.

- Producción de 70.000 ha de cultivo

- Alrededor de $2.000 \mathrm{Tm} /$ año de certificación el marco legal y el comercial. CETER S. Coop.

- Distribuye más de $20.000 \mathrm{tm}$ de fertilizantes.

- 30 surtidores de gasóleo agrícola que distribuye más de 6 millones de litros.

https: / / www.youtube.com/watch?v=UUTxj4tK4Y

Revistas

http://cerealesteruel.com/revistas/ 
En Sariñena se encuentran las oficinas centrales, así como los almacenes de venta, la planta de fertilizantes, un Centro de Formación, la planta deshidratadora, el laboratorio y el taller propio.

Posee la Cooperativa además dos plantas de secado ubicadas en

Cooperativa los Monegros

Creada en 1963 y se dedica dedicada a la producción, transformación y comercialización de cereales y alfalfa.

Con sede central en Sariñena, dispone además de una amplia red de almacenes y pistas en la zona de Monegros que acercan la Cooperativa al campo y a sus casi 500 socios.

ttps: //www.cooperativalosmone gros.es/servicios
Villanueva de Sijena y Lalueza con una gran capacidad de almacenamiento. Completan la red de infraestructuras en la comarca de Monegros una serie de centros de menor capacidad en San Juan del Flumen, Huerto, Pallaruelo y Castejón de Monegros o los de Valfarta y San Lorenzo del Flumen. A los que se unen las pistas de Lastanosa y

Castelflorite.

- Ofrece servicios de: comercialización, distribución, profesionales para al agricultura, departamento técnico agrícola, combustibles, laboratorio

- Datos básicos. 500 socios de Ballobar, Castejón de Monegros, Castelflorite, Huerto, La Lueza, Lastanosa, Pallarueo San Juan de Flumen, San Lorenzo de Flumen, Sariñena, Valfarta, Villanueva de Sijena, 60 trabajadores

- Vídeo Corporativo

https: / / www.youtube.com/ watch?v=Fv fwHyL2aOc 
fundación rey ardid

\section{Fundación \\ Rey Ardid}

La Fundación Rey Ardid nace en 1991 para atender a personas con problemas de salud mental, ampliando posteriormente los colectivos: niños y adolescentes, mayores, personas con discapacidad y personas en riesgo de exclusión social, para lo que ha creado el Grupo Rey Ardid, que agrupa diferentes entidades sin ánimo de lucro.

Rey Ardid es un conjunto de organizaciones que desarrolla actividades dirigidas a la atención, cuidado e integración de personas vulnerables, generando servicios y entornos facilitadores de una mayor autonomía personal, mediante una gestión eficiente de los recursos disponibles y situando a la persona en el centro de todas sus actuaciones.

\section{https: / / reyardid.org/}

https: / /www.youtube.com/user/gruporeyardid https://www.facebook.com/FundacionReyArdid
El objetivo del Grupo Rey Ardid es diseñar itinerarios de atención y rehabilitación completos que favorezcan la integración de las personas con dificultades en un entorno social, vital y laboral normalizado.

\section{Datos básicos:}

Usuarios: 5.715 personas

Empleo: 773 profesionales

Voluntarios: 100 personas

Facturación: 37,8 millones de euros

Participa al 100\% en 7 empresas: Naturardid S.L., Integrardid S.L., UTE Integrardid S.L. y Naturardid S.L., UTE Integrardid S.L. y FERDOM S.L., Rey Ardid S.L, Rey Ardid La Rioja S.L. y Cierzo Gestión, S.L.

- Participa en el órgano de Gobierno y gestiona 6 fundaciones: Fundación Jaime Dena de Almudevar, Fundación Residencia de Ancianos de Gurrea, Fundación Rey Ardid, Impulso y Fermín Alegre UTE (Cedrillas), Fundación Rey Ardid y Vida a los años UTE (Belchite), y Fundación Baruca.

- Participa exclusivamente en el órgano de Gobierno de 6 organizaciones: Fundación Atención Temprana, Fundación para la Acción Social de los Monegros, Somontano Social S.L., Albertia Servicios Sociosanitarios SLU - Fundación Rey Ardid UTE Plata Castañar, Albertia Servicios Sociosanitarios SLU - Fundación Rey Ardid UTE Las Vegas Cienpozuelos, y Albertia Servicios Sociosanitarios, SLU - Fundación Rey Ardid UTE Valle de La Oliva.

- Mantienen un contrato de gestión de 2 entidades: Gestión de Residencias Geriátricas, S.L., Sociedad Municipal Gestión de Residencias Valdeolivo, S.L. 


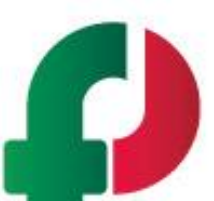

FUNDACIÓN PICARRAL

\section{Fundación Picarral}

La Fundación Picarral es una entidad sin ánimo de lucro zaragozana constituida en 1992, aunque sus primeras iniciativas se remontan a principios de la década de 1980 . Esta experiencia está estrechamente ligada al barrio del Picarral y a la entidad que, en sus orígenes, fue su promotora: la Asociación de Vecinos y Vecinas PicarralSalvador Allende.

La misión de la Fundación Picarral consiste en realizar una labor formativa y educativa de calidad que favorezca la inserción sociolaboral de personas, especialmente jóvenes, que por diferentes razones han quedado fuera de los procesos regulares de integración social. En consecuencia, la Fundación trabaja mediante la formación y la inserción sociolaboral por la igualdad de oportunidades de todos los jóvenes para prevenir la exclusión social y evitar que las diferencias se conviertan en desigualdades, ya sean de carácter social y/o educativo.
Los valores que guían la actividad económica de la Fundación Picarral son la Calidad y mejora continua; el Liderazgo, autonomía y colaboración; la Transformación y responsabilidad social, equidad y solidaridad; la Honestidad, respeto y transparencia; la Innovación y dinamismo; la Beligerancia frente a la injusticia; la Confianza, apoyo, trabajo en equipo y reconocimiento; y los Cuidados.

\section{Datos básicos (2016)}

Número de personas participantes en proyectos: 324

- Empleo: 31 personas con contrato indefinido y 3 con contrato temporal (15 mujeres y 19 hombres)

- Ingresos de la entidad por su actividad propia: 1,3 millones de euros

La Fundación Picarral participa en la empresa de inserción MAPISER S.L. y en los centros especiales de empleo CESERPI , S.L. y ARAPACK, S.L.

- Además, está presente en las siguientes redes o plataformas: Red de Centros Sociolaborales del Ayuntamiento de Zaragoza, Federación Abanico, Red Aragonesa de Entidades Sociales para la Inclusión, Federación ENLINEA, CERMI Aragón, Coop57 Aragón, PADIS (Patronal Aragonesa de la Discapacidad) y AREI (Asociación Aragonesa de Empresas de Inserción).

https: / / fundacionpicarral.org/ https://www.facebook.com/Fundacion-Picarral 


\section{Principales servicios:}

\section{ADUNANARE}

\section{Fundación}

\section{Adunare}

Fundación Adunare nace en el año 2000 a raíz de la unión de ocho entidades surgidas de la iniciativa social en la ciudad de Zaragoza.

Fundación Adunare tiene por objeto la promoción e integración social, educativa, cultural y laboral de las personas con necesidades de promoción e integración por motivos culturales, educativos, sociales o laborales. Dicha integración se realiza primordialmente mediante la formación cultural, en especial en los conocimientos y habilidades sociales básicos; la formación sociolaboral para la adquisición de conocimientos y técnicas que faciliten la búsqueda y obtención de empleo y la práctica profesional y laboral tutelada.

La Fundación atiende a los colectivos de infancia, juventud, población adulta en exclusión, salud mental, inmigrantes y mujeres, demás de realizar procesos de intervención comunitaria.
Centro de Tiempo Libre El Cuco

Centro Municipal de Tiempo Libre ZardachoOliver

Proyecto de Animación Deportiva Oliver

Educación de Calle Oliver-Valdefierro

Centros Sociolaborales (Delicias, San José, Oliver, Torrero, Valdefierro, La Jota, Almozara y Las Fuentes)

- Centro de Educación de personas adultas Codef Adunar

- Servicio de apoyo a la mediación intercultural SAMI

- Centro Comunitario de Oliver

Centro de Inserción Laboral

Centro de Día Torrero

Servicios Parque Delicias S.L.U.

Más Manos

Consolida Oliver S.L.U.

\section{Empresas de Inserción:}

Más Manos

Consolida Oliver, S.L.

\section{Centro Especial de Empleo:}

Servicios Parque Delicias, S.L.

\section{Datos básicos (2016)}

Personas voluntarias: 190

Personas trabajadoras contratadas: 150

El $62 \%$ de los puestos ocupados por mujeres

El 76\% de los contratos son indefinidos

Ingresos de la entidad por su actividad propia: 4,2 millones de euros

http://www.adunare.org/

https://www.facebook.com/Fundacion-Adunare 


\section{Grupo Arcoiris}

Su origen se remonta a 1978, con la constitución de una fábrica de piensos. El grupo cooperativo se encuentra ubicado en la comarca del Matarraña, en Teruel. Su lema "la unión hace la fuerza". El grupo y las empresas que lo conforman ha recibido múltiples reconocimientos y premios a su labor de forma continuada desde que en 1988 la DGA le concediese a GUCO la medalla al mérito social. Entre otros, durante varias ediciones ha recibido premio de Calidad al Jamón D.O. ( Feria del Jamón de Teruel). Distinción Federación Aragonesa de Cooperativas Agrarias (FACA).

http://www.grupoarcoiris.com/
- El Grupo Arcoiris es uno de los principales grupos ganaderos de Aragón. Su objetivo inicial fue producir piensos para abastecer al ganado porcino. Se introduce en los sectores cunícola y ovino. A través de nuevas sociedades y participando en otras diversifica e integra la producción, para dar un mejor servicio a los socios y para garantizar la calidad.

- El Grupo Arcoiris apuesta por la calidad. Asegura la trazabilidad alimentaria al $100 \%$. Todos los procesos de producción son propios. Ejemplo de trabajo en equipo y cooperativa de referencia. Se implica socialmente con el territorio.

\section{Datos básicos:}

620 socios

- 300 trabajadores

80.000 Toneladas

- 90.000 piezas carne comercializada

SOINCAR, mayor productor jamón denominación de origen.

- 5 sociedades de base, otras 15 sociedades de primer grado y 13 empresas participadas. ( 3 Reyes, Aviba, BisMat Bricas, Centro de Jardinería, CIAR, Correduría Arcoiris, Cotécnica, ESYPU, Fenie, Geinval, Gestoría Arcoíris, Granjas GUCO, GUCO, INCO, Insinec, Lavados y limpiezas, Matadero Comarcal, Montajes Generales Matarraña, Sergan, Sersuco, Soincar, Transarcoiris)

https: / / www.youtube.com/watch?v=jhPqXYoOn3U

Revista

http://www.grupoarcoiris.com/images/stories/pd $\underline{\text { f/Revista19.pdf }}$ 
- ARS ALENDI está constituida y participada por las cooperativas Virgen de la Corona de Almudévar (40 por ciento) Virgen del Rosario (39 por ciento) y San Mateo Apóstol de San Mateo de Gállego (uno por

\section{Grupo Ars Alendi} ciento), la Cooperativa Santa Orosia de Jaca (10 por ciento) y la Cooperativa Ganadera de Caspe (10 por ciento). .

- Ofrece servicios de: fabricación de piensos y ganadería de porcino. Durante estos años la estrategia de la empresa ha ido adaptándose a la coyuntura actual, manteniendo el fundamento empresarial

Creada en 2003 surge de la necesidad de varias cooperativas de tener que ampliar sus fábricas de piensos para adaptarse a la nueva legislación. La alternativa a esas ampliaciones era unirse, y crear una nueva fábrica, con la que acometer un proyecto a futuro mucho más ambicioso en Gurrea de Gállego

\section{http: / /alendi.es/} de este grupo, que es transformar nuestra materia prima y cereales en pienso y carne, y hacerlo de una manera eficiente dando un servicio integral a nuestros socios y clientes. Se trata de implementar una nueva economía, circular, basada en el principio de «cerrar el ciclo de vida» de los productos a la vez que se genera empleo estable.

- Datos básicos. ARS ALENDI, que comercializa sus productos con el nombre de ALENDI, genera 22 puestos de trabajo directos y 20 indirectos.

- Vídeo Corporativo 25 https: / / www.youtube.com/watch?v=Ro1tY A8Siss 


\section{pastores}

\section{Grupo Pastores}

Grupo PASTORES es una empresa Cooperativa aragonesa con más de 35 años de experiencia dedicado al sector cárnico ovino principalmente.

Es el resultado de la unión de tres empresas cooperativas enfocadas al sector cárnico ovino: CarneAragón, APA Cinco Villas y Cotega, las cuales se unieron creando una gran cooperativa de ovino con 1500 socios aragoneses y de provincias limítrofes y con un volumen de 500.000 ovejas.

\section{https: //www.grupopastores.coop/}

https: //www.youtube.com/watch?v= VGEPUpCjCq8
- Grupo Pastores ha sido galardonado con diversos premios a nivel regional, nacional y europeo. Destacan los premios de Mejor empresa alimentaria Española en Innovación en el año 2007, así como el premio a la Mejor Cooperativa Agroalimentaria Europea en el año 2009.

- Pastores trabaja por y para el medio rural, conservando la población, el territorio y los medios naturales. Una de las principales misiones del grupo es asegurar la rentabilidad y sostenibilidad de una forma de vida de tradición milenaria, como es el pastoreo en los campos y medio naturales de Aragón.

\section{Cifras 2016}

- Ingresos 2017: 31.997.856€

- Empleo: Cerca de 1500 socios y más de 800 pastores aragoneses conforman este grupo cooperativo.

- Cuentan con más de 500.000 cabezas de ganado ovino, su principal actividad económica. 


\section{Amapiser}

\section{MAPISER}

Mapiser es una empresa de inserción creada en 1998 por la Fundación Picarral y la Fundación Integración y Empleo. Ofrece servicio

Mapiser participa en el mercado social de Aragón y en la Asociación Aragones de Empresas de Inserción - AREI.

\section{https://mapiser.com/}

- Mapiser (Manipulados y Servicios Picarral, S.L). es una empresa de inserción, una iniciativa empresarial vinculada a la economía social aragonesa a través de una estructura dinámica e innovadora.

Siguiendo metodologías de inserción laboral, que beneficien a las personas con especiales dificultades de entrada al mercado de trabajo ordinario, Mapiser ofrece en su ámbito unos modelos de excelencia empresarial que prestan atención al trabajador en todos sus procesos organizativos.

- Ofrece servicios de: manipulados. Embolsados y retractilados; mantenimiento mobiliario urbano y vía pública; documentación y digitalización de datos, gestión de contenidos; web, gestión de archivos, manipulación y control.

- Datos básicos. 56 trabajadores, dos centros de trabajo en Zaragoza 
mercado Social

MESCOOP - COOPERATIVA DE SERVICIOS

\section{MESCoop Aragón, servicios para el mercado social}

MESCoop Aragón es una cooperativa de servicios que compone una red de producción, distribución y consumo de bienes y servicios con criterios éticos, democráticos, ecológicos y solidarios, constituida por empresas y entidades de la economía social y solidaria, junto a consumidores/as, individuales y colectivos.

MESCoop Aragón ha sido promovida por la Red de Economía Alternativa y Solidaria de Aragón (REAS Aragón).

A nivel estatal, hay otros Mercados sociales en Madrid, Euskadi, Navarra, Cataluña e Islas Baleares.
- En MESCoop Aragón pueden participar entidades, personas o colectivos interesados en un consumo responsable y solidario, ya sea como socios de servicios (entidades de proveedores) y socios colaboradores (de consumo).

- Integra a 47 entidades con actividad económica.

- El volumen de facturación conjunto es de 13,5 millones de euros, de los cuales el $66 \%$ se destina a gasto de personal y un 7\% a la intercooperación con otras entidades del Mercado Social Aragón.

- Se ubican en 27 actividades económicas, en todas las fases del ciclo económico: producción, distribución, consumo y financiación.

- https://mercadosocialaragon.net/

- https://www.youtube.com/watch?v=E g8STaN3Zo4 


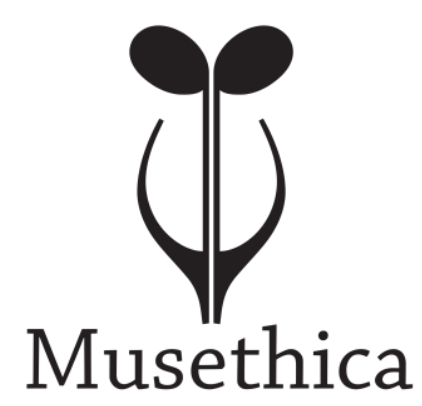

\section{Musethica}

La asociación Musethica se creó en Zaragoza a finales de 2012 con el objetivo de, por un lado, promover, fomentar y difundir la música clásica, especialmente a las personas que no tienen fácil acceso a la misma, y por otro, apoyar el aprendizaje de los jóvenes músicos que de forma voluntaria y gratuita colaboran para difundir la música clásica a los colectivos anteriores. Desde entonces se ha expandido con sedes en Alemania (2013), Israel (2014), Polonia (2015) y Suecia (2016), y colabora regularmente con Austria, China y Francia
- Desde su creación y hasta septiembre de 2018 las Asociaciones Musethica han realizado más de 1.400 conciertos en ocho países diferentes, con 275 músicos de veintiocho nacionalidades, llegando a una audiencia de 70.000 personas, con la participación de más de 500 centros sociales.

- Desde 2012, Musethica en España ha celebrado 467 conciertos, siendo, además de la asociación fundadora, la asociación Musethica con más actividad. 160 músicos, 24 de ellos profesores de prestigio internacional y 136 estudiantes de alto nivel, han participado en estos conciertos, de los cuales 422 han tenido lugar en Zaragoza, siendo la ciudad con mayor número de actividades entre todas las asociaciones Musethica con la colaboración de más de 110 centros sociales diferentes.

- El modelo educativo de Musethica tiene un claro impacto en los músicos y en la sociedad. Los jóvenes músicos mejoran considerablemente sus capacidades interpretativas y desarrollan una nueva manera de comprender la música y su rol como músicos profesionales en la sociedad y, al mismo tiempo, se da la oportunidad de asistir a conciertos y de recibir los beneficios de la música clásica a personas que de otro modo no tendrían la oportunidad de ello.

- https://www.musethica.org

- https://www.youtube.com/watch?v=3pTPAPvy9b4

- https://www.youtube.com/watch?v=mp9jLlFWlzs 


\section{San Juan}

\section{Bautista Soc.}

\section{Coop. Ltda.}

La bodega cooperativa San Juan Bautista fue construida en el año 1955 como principal herramienta comercial que permitiese a numerosos agricultores dar una salida razonable a sus producciones ante las diversas bodegas particulares que existían en Fuendejalón. Con el paso de los años la cooperativa fue creciendo y hoy en día podemos afirmar que engloba al $99 \%$ de los viticultores de la zona

http://www.coopfuendejalon.com I
Asimismo, la bodega, con capacidad para 17 millones de litros y como elemento vertebrador de la cooperativa, ha sufrido profundas transformaciones en los últimos años, gracias a las cuales podemos afirmar que tenemos una bodega tecnológicamente moderna y con los medios más avanzados para la elaboración de unos caldos que cada día requieren más atención y esfuerzos por parte de todos.

- Los viñedos de los socios que componen la cooperativa también han sido sometidos a mejoras en los últimos años: la transformación a espaldera de varios cientos de hectáreas para prevenir los efectos adversos de las heladas, la plantación de las variedades mejorantes ya mencionadas, la implantación de tratamientos coordinados y controlados por un ingeniero técnico propio de la cooperativa 0 la incentivación económica para evitar el arranque de parcelas de garnachas centenarias, son un buen ejemplo de la filosofía que está siguiendo esta Bodega con mentalidad netamente empresarial.

- Vídeo Corporativo

- https://www.youtube.com/watch? $=M$ RjdFN3502U 


\section{tiebel

\section{Tiebel S.Coop}

Tiebel es una Empresa de iniciativa social para la prestación de servicios de calidad a la comunidad en los ámbitos de la limpieza profesional, la formación ocupacional y los servicios sociales, siendo estas actividades el vehículo principal para alcanzar su objeto social: la generación de puestos de trabajo, preferentemente para la mujer.

Constituida en Azuara (Zaragoza) en 1993 como cooperativa de Iniciativa Social, surge como respuesta a la situación de desempleo de un grupo de personas que sabían y querían trabajar. Se comienza a prestar servicios de Ayuda a Domicilio, Limpieza Profesional, Gestión de Establecimientos, Pintura, Jardinería en la Comarca Tierras de Belchite.

\section{Datos generales:}

- Tiebel - 97 personas contratadas.

- Tinser - 22 personas contratadas.

- Distintivo de Igualdad en la empresa

- Sello RSA de Responsabilidad Social en Mención especial en el II Premio Ebrópolis a las Buenas prácticas Ciudadanas

- Certificación ISO 9001 de normas sobre calidad y gestión de calidad
En 2007 promueve y constituye una nueva iniciativa empresarial, TIEBEL SERVICIOS DE INSERCIÓN, S.L.U. (Tinser, S.L.U.).

Su misión es proporcionar a personas en situación de riesgo de exclusión social, especialmente a mujeres, una estabilidad económica y un itinerario personalizado de formación y acompañamiento para mejorar sus condiciones de empleabilidad y facilitarles el acceso al mercado laboral ordinario.

\section{aRopa2}

Desde el año 2013, Tiebel y Grupo La Veloz promueven el proyecto aRopa2, que consiste en la recogida, reutilización, reciclaje, venta y entrega social de ropa y otros textiles, y que se realiza a través de nuestra empresa Tiebel Servicios de Inserción, S.L.

\section{http://tiebelcooperativa.com}

https://www.youtube.com/watch?v $=$ kKLhLcj3uv4

https://www.youtube.com/watch?v $=$ YKSfzyhCjDQ 


\section{Casos de Empresas de Economía Social España}




\section{Coop57, Sccl}

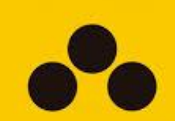

$\operatorname{coop} 57$

servicios financieros éticosy solidarios

Coop57 es una cooperativa de servicios financieros y como tal realiza actividad financiera. Recoge ahorro popular de la ciudadanía para canalizarlo hacia la financiación de proyectos de economía social y solidaria que creen ocupación, fomenten el cooperativismo, el asociacionismo y la solidaridad en general, y promuevan la sostenibilidad sobre la base de principios éticos y solidarios.

\section{Historia}

Los orígenes de Coop57 se remontan a la lucha de los trabajadores de la Editorial Bruguera. Cuando la editorial cerró en 1986, y después de un largo procedimiento judicial, en 1989 un grupo de 80 antiguos trabajadores creó un fondo colectivo con parte de las indemnizaciones recibidas. Una parte de ese fondo $(178.000 €)$, se destina para financiar proyectos autogestionarios de creación de puestos de trabajo. Este fondo es el origen de Coop57, creado el 19 de junio de 1995.

En un primer periodo, hasta 2001, Coop57 definió su modelo jurídico y de funcionamiento y se empezaron a realizar las primeras operaciones crediticias.

En una segunda etapa, a partir del 2001, Coop57 decidió ampliar su base social y su ámbito de actuación fuera de Catalunya. Paralelamente, fue creciendo también su base de personas socias colaboradoras, buscando abrirse a la ciudadanía comprometida.

\section{Datos Generales}

- Coop57 se estructura en la actualidad en 6 secciones territoriales (Catalunya, Aragón, Madrid, Andalucía, Galiza y Euskal Herria), cada una de las cuales tiene sus propios órganos y estructuras de participación.

- Datos sociales. Integra a 799 entidades socias de servicios y a 3.881 socias colaboradoras.

- Datos económicos. El saldo de las aportaciones de los socios y socias colaboradoras en 2017 fue de 35.502.171€. El volumen anual de préstamos concedidos en 2017 fue de 16.633.159€.

\section{https://coop57.coop}

https: / /www.youtube.com/watc $\underline{\mathrm{h} ? \mathrm{v}=\text { IrXVZeLX7NI }}$

https: / / www.youtube.com/watc $\mathrm{h} ? \mathrm{v}=\mathrm{AUSdOaRNtjk}$
33

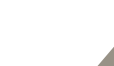


La Fundación Espriu tiene por objetivo la promoción, la investigación y la divulgación de la gestión cooperativa de la sanidad. la cual propone una relación directa médico-paciente, la libre elección del médico y el pago directo por el tratamiento médico, y una estructura participativa y autogestionada, basada en la falta de beneficio económico y la ayuda mutua

\section{Fundación}

\section{Espriú}

La Fundación Espriu es una entidad privada sin ánimo de lucro creada en 1898 como resultado de las entidades creadas por el Dr. Josep Espriu desde 1957 bajo la filosofía del cooperativismo sanitario integral.

Este grupo de empresas facturó 1.787.921.758 millones de euros en 2017, y se ha convertido en el cuarto grupo sanitario cooperativo del mundo, según el ranking de la Alianza Cooperativa Internacional $(\mathrm{ACl})$.

www.fundacionespriu.coop/

\section{Datos básicos:}

- La Fundación Espriu agrupa a 4 entidades: dos compañías de seguros (ASISA y Assistencia Sanitatia Col-legial - ASC), dos cooperativas de médicos (Lavinia y Autogestió Sanitaria) y una cooperativa de consumidores (Scias), que se organizan en dos secciones: una en Barcelona (incluyendo ASC, Autogestió Sanitaria y Scias) y otra a nivel estatal (ASISA y Lavinia agrupados).

- ASISA se ha convertido en la tercera aseguradora en facturación .

- Editan la Revista Compartir, con una tirada de 30.000 ejemplares, en 3 idiomas.

- Socios cooperativistas: 182.850 socios

Doctores: 38.766 médicos

Empleados: 45.388 personas

- Usuarios asociados: 2,264,966 personas

Facturación: 1.685 millones de euros

Activos: 742 millones de Euros

https: / /www. linkedin.com/company/fundaci\%C3\%B3 n-espriu/?originalSubdomain=es

https://twitter.com/espriu_f?lang=es 


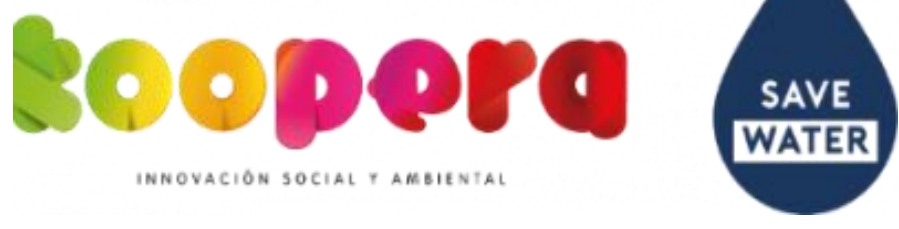

\section{Red Social \\ Koopera S. Coop}

La Red Koopera es una Cooperativa sin ánimo de lucro de segundo nivel que reagrupa a 19 entidades sociales presentes en 11 provincias de España impulsadas por Cáritas. Inició su andadura en 1990, busca la generación de empleo para personas en situación de vulnerabilidad social a través de empresas de inserción que realizan procesos individuales de Inclusión Activa.

\section{http://koopera.org/}

http://koopera.org/koopera-enimagenes/7841/

https: //www.facebook.com/Koopera/
Koopera tiene por objetivo la inserción sociolaboral de personas en situación ó riesgo de exclusión social, mediante actividades de servicios ambientales, reutilización y reciclaje, consumo sostenible, formación, atención a personas y otras actividades que pueden ayudar a cumplir su misión. El objetivo es facilitar el paso a la empresa ordinaria. Ofertan actividades de capacitación habilidades sociales y laborales, y para la incorporación como socios a las cooperativas en las que se facilita la participación y el emprendizaje. Sus acción se guía por Innovar y Crecer, con las personas como centro y se desarrolla sobre las competencias cooperativas.

\section{Datos básicos:}

- Está formada por las cooperativas y entidades sociales: Alkarbiziz, Berjantzi, Berzioarso, Cáritas Koopera Astur, Ecolabora, Ekorropa, Koopera Ambiente, Koopera Consulting, Koopera Mediterránea, Koopera Servicios Ambientales, Koopera Servicios Sociales y Formación, Zaintzalan, Oldberri, Reciplana, Arropa, Cáritas Koopera Almería y Recuperaciones El Sembrador. Participa de la sociedad mixta Berziklatu.

- 2 proyectos internacionales Romania - Chile.

- Áreas destacadas: servicios sociales y formación; servicios ambientales; reutilización y reciclaje; Koopera Store

- Más de 500 voluntari@s de Cáritas

- 243 Empleos de inserción

- 433 Personas trabajadoras

61.643 Miembros del Club Koopera

- 6.819 Atención a personas necesitadas 


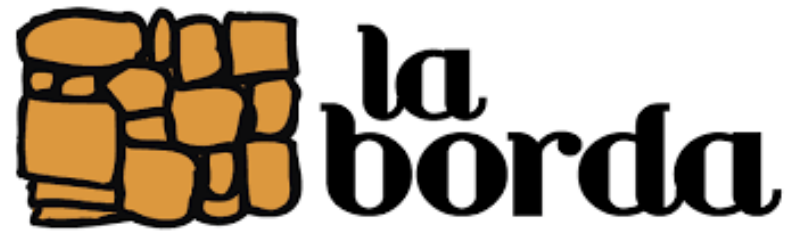

Cooperativa d'habitatge en cessió d'ús

\section{La Borda Cooperativa} d'habitatge en cessió d'ús

La Borda se conforma por más de una cincuentena de personas de todas las edades, y vinculadas al conjunto Can Batlló, que pretenden armonizar la necesidad de acceder a una vivienda digna, social, asequible y ambientalmente sostenible con la voluntad de fomentar nuevas formas de convivencia y de generar comunidad a través de la interrelación entre vecinos y vecinas. En definitiva, la cooperativa busca un reparto justo del trabajo doméstico y de los cuidados, una manera de estar y de hacer en común que encarne los valores de la economía feminista y de la economía social y solidaria.

El modelo en cesión de uso se utiliza de manera significativa en Alemania, Uruguay y Dinamarca. En este último país, más del $20 \%$ de las viviendas unas 120.000 - no son ni de compra ni de alquiler. De este modo, la propiedad del edificio siempre recae en la cooperativa - nunca es individual- y esto evita que los pisos se puedan revender a un precio más caro, o alquilarlos con ánimo de lucro: el precio de los pisos siempre es el mismo y lo decide la cooperativa colectivamente. Dicho en pocas palabras: se trata de un modelo de acceso a la vivienda no especulativo.
Objetivos

- Garantizar el acceso a una vivienda digna y asequible.

- Desmercantilizar el alojamiento para evitar usos especulativos.

- Generar un proceso colectivo de definición de un nuevo modelo de producción, gestión i tenencia de la vivienda alternativo.

- Producir nuevas formas de convivencia, de vínculo social i de autoorganización.

- Fomentar les relaciones igualitarias entre las personas, la relación intergeneracional y la igualdad entre géneros y etnias.

- Convertirnos en una alternativa generalizable en el ámbito de la vivienda pública, articulando un modelo de vivienda protegida accesible para la gente con rentas bajas.

- Construir un barrio autogestionado a escala humana en Can Batlló, desde el compromiso responsable con el territorio y la generación de otro tipo de urbanismo.

- Aprovechar al máximo los recursos existentes y reutilizarlos de una forma ecológica y sostenible.

http: / / www.laborda.coop/ 36

https://www.canbattlo.org/ 


\section{latraviesa}

\section{Asociación La Traviesa} Red por la Economía Solidaria

\section{La Traviesa es una red de cooperativas y entidades por la Economía Solidaria}

Es una asociación flexible, abierta, participativa y democrática que agrupa a empresas, trabajadores y trabajadoras que construyen alternativas desde la realidad cotidiana.

El cooperativismo es su referencia principal, se recuperan sus valores originales y se complementan para responder a nuevas necesidades sociales.

La autogestión, con clara responsabilidad social y ecológica es un modelo de organización y consumo idóneo para construir una Economía al servicio de las personas.

https: / / www.economiasolidaria.org/e ntidades/asociacion-la-traviesa
Objetivos

- Democratizar la Economía

- Construir relaciones laborales más equitativas y participativas

Basar las relaciones comerciales en criterios de justicia, honestidad y respeto medioambiental

- Sensibilizar a la ciudadanía hacia el consumo responsable

- Favorecer un reparto equilibrado de la riqueza

- Avanzar en la construcción de una perspectiva de género

- Producir bienes y servicios con un fin social

- Integrar a las personas excluidas laboralmente

\section{Datos básicos}

- Año de constitución: 2008

- Año de inicio de la experiencia: 2005:

- Redes / Grupos: REAS Madrid, Mercado Social de Madrid 


\section{SMart \\ de gestión de proyectos \\ artísticos y culturales}

\section{Smart lbérica de Impulso Empresarial S.C.A.}

SMartlb tutoriza la gestión de proyectos creativos y culturales, ofreciéndoles a sus socios y socias asesoramiento para desarrollarlos, formación para mejorar su capacitación, y servicios mutualizados para que puedan desarrollar su actividad profesional en un marco legal adecuado.

SMart es la abreviatura de la expresión francesa Societé Mutuelle pour Artist, una organización sin ánimo de lucro que se puso en marcha en Bélgica en 1994 bajo el nombre de SMartBe.
SMartlb forma parte de un proyecto europeo impulsado por la entidad belga SMartBe, en el que están implicados actualmente 9 países con la finalidad de crear una red europea cooperativa, SMart, que permita la movilidad de sus socios y socias, y facilite la tarea administrativa y fiscal de los trabajos transfronterizos de todos sus miembros.

SMart Ibérica acompaña a: artistas plásticos y visuales, fotógrafos, camarógrafos, diseñadores gráficos, textiles y web, ilustradores, artistas escénicos y circenses, actores, escenógrafos, músicos y compositores, escritores, guionistas, artesanos, gestores culturales, productores audiovisuales, comisarios y críticos de arte, representantes de artistas, técnicos de sonido e iluminación, informáticos, programadores, intérpretes del patrimonio, distribuidores de cine y teatro, traductores, formadores, comerciales y a todas aquellas profesiones que se desarrollan en el marco creativo.

SMartlb se articula dentro de la Economía Social, su interés activo reside en el bien colectivo y el interés social. Es una empresa sin ánimo de lucro que tiene como compromiso reinvertir los beneficios obtenidos en la propia estructura y en lo que decidan sus socios y socias de manera democrática.

\section{Datos básicos}

- Delegaciones en Barcelona, Burgos Granada, Madrid, Málaga, Sevilla y Zaragoza.

https://smart-ib.coop/ 


\section{Sم Soin energia}

\section{Som energia}

Som Energia es una cooperativa de consumo de energía verde sin ánimo de lucro. Sus principales actividades son la comercialización y producción de energía de origen renovable.

Su objetivo y compromiso es impulsar un cambio del modelo energético actual para conseguir un modelo $100 \%$ renovable.

\section{Cifras 2018}

- Número de socios/as:52.385

- Número de contratos:84.497

- Producción:11,80 GWh/año

- Número de empleados/as: 7 personas
El proyecto de creación de la cooperativa se inició en noviembre de 2009 por un grupo de antiguos alumnos y profesores de la Universidad de Gerona y otros colaboradores, con la intención de seguir los pasos de iniciativas como Ecopower(Bélgica), Enercoop (Francia) y Greenpeace Energy (Alemania).

- La iniciativa de Som Energía replica un modelo de cooperativas de energía verde muy consolidado en Europa.

- Sin comerciales clásicos, la entidad gestiona más de 84.000 contratos en toda España.

- Se busca producir la misma cantidad de energía que consumen los socios/as.

- Las plantas de producción se han podido financiar sin créditos bancarios; sólo con aportaciones de los socios/as.

\section{https: //www.somenergia.coop}

https: / / www.youtube.com/watch?v=9Sw kKQZIOzU 


\section{( tasubinsa}

TASUBINSA

Tasubinsa es una entidad sin ánimo de lucro, declarada por el Gobierno de Navarra de Utilidad Pública e Imprescindibilidad.

Su objetivo principal es la integración de las personas con discapacidad intelectual y del desarrollo, generando oportunidades laborales y de ocupación, siempre adaptadas a las capacidades individuales de cada persona.

http://www.tasubinsa.com/
Tienen dos principales modalidades actuación:

- Centro especial de Empleo: En la modalidad de Empleo, cuentan con más de 800 empleados y trabajan para 200 clientes, realizando trabajos de subcontratación industrial y de servicios.

- Servicio de centro ocupacional: En Tasubinsa atienden a 600 personas con discapacidad intelectual y del desarrollo que presentan graves dificultades para acceder al empleo ordinario o protegido.

Cifras 2017

- Ingresos 2017: 30.686.561€

- Empleo: 1.418 personas, el 86\% de ellas con algún tipo de discapacidad.

- 13 centros de trabajo en Navarra y más de 200 clientes.

- 28 años de trayectoria 


\section{Casos de Empresas de Economía Social Iberoamérica}


- Cooperativa Agrícola de Mujeres 4pinos surgió de la iniciativa de tres mujeres productoras de hortalizas del altiplano central de Guatemala y de una larga vinculación con la Cooperativa

Cooperativa integral agrícola mujeres 4pinos (Guatemala)

1era Cooperativa Agrícola de mujeres de Guatemala

http://www.mujerescuatropinos.com/ 4pinos. A partir de entonces el crecimiento de la cooperativa, mejor conocida como mujeres 4 pinos, ha sido acelerado al grado qué, en la actualidad tiene más de 275 mujeres miembros de diferentes comunidades del altiplano

- Los principales cultivos son el ejote francés (alrededor de 850 cuerdas cultivadas) y diferentes variedades de arveja. Cultivamos además variedad de hortalizas tales como succhini comander y sunburst, mini zanahoria y radiccio. Para mejorar su ventaja competitiva se encuentran en proceso de certificar nuestros productos.. han logrado consolidar una experiencia de exportación de hortalizas a Estados Unidos 
- Actualmente existen 50

cooperativas afiliadas, agrupamos a más de 1200 familias productoras del cacao orgánico.

\section{Central de Cooperativas El Ceibo (Bolivia)}

Es una Organización Cooperativa de Segundo grado que trabajan enmarcados bajo la Ley General de Sociedad de Cooperativas de Bolivia, creada en 1977

http://www.elceibo.com/
- Su misión es desarrollar con transparencia y eficiencia la administración de la cadena productiva del cacao orgánico.

- Bajo principios de unidad, sostenibilidad, justicia social y equidad.

- Con recursos humanos propios formados bajo la filosofía del cooperativismo, cuyo fin es resolver las necesidades de las cooperativas afiliadas y sus socios. Contribuyendo al desarrollo Regional y Nacional.

- https://www.youtube.com/watch? $\mathrm{v}=\mathrm{G} 9 \mathrm{etbVk} 3 \mathrm{bmc}$ 


\section{Meri Henua Coop (Chile)}

Meri Henua, la cooperativa rapanui que protege a las abejas y que produce una miel única en el mundo.

Un estudio determinó que las abejas de Isla de Pascua no están infectadas por ninguna plaga, haciéndolas únicas en su especie. Por esa razón, esta organización se preocupa de mantenerlas sanas y protegidas.

https://cooperativas.emol.com/notic ias/meri-henua-cooperativa-rapanui/
- la Cooperativa Apícola Meri Henua, organización compuesta por 13 personas cuya principal función es también proteger a las abejas de rapanui.

- Los integrantes de Meri Henua cumplen distintas tareas que incluyen la polinización, la producción de miel y mermelada y el diseño orgánico de los huertos. Su presidenta, Diana Edmunds Tucki, dice que si bien en Meri Henua valoraron los beneficios económicos, también pensaron que sus abejas requerirían de un cuidado especial.

- Dentro de los próximos desafíos de la cooperativa está obtener la Indicación Geográfica, un sello que entrega el Instituto Nacional de Propiedad Industrial (Inapi) que serviría para evitar que se comercialice falsamente miel como si fuera de la Isla, cuando en realidad no lo es.

- "Una sabe la cantidad de miel que se produce aquí, pero que de repente se adultera y para evitar estas prácticas queremos sacar este sello.

- https://www.youtube.com/watch? $\mathrm{v}=\mathrm{ahN}$ TG9BBT3A\&t $=46 \mathrm{~s}$ 
- Sus actividades van desde la producción de café orgánico de exportación, pimienta gorda y miel melipona (abeja sin aguijón que aprovechaban los pueblos originarios mesoamericanos), hasta proyectos económicos y comunitarios como la Caja de Ahorros Tosepantomin, de salud como Tosepan Pajti o turismo como Tosepan Kali

\section{Tosepan (México)}

El Movimiento Cooperativo Indígena de la Sierra Nororiental de Puebla se inició en 1977 y se formalizó en 1980 con la constitución de la Cooperativa "Tosepan Titataniske" (Unidos Venceremos, en náhuat). Los socios fundadores se propusieron encontrar solución al problema de la carestía de los productos básicos para la alimentación de las familias, ya que en aquellos tiempos era la demanda más sentida por toda la población. http: //www.tosepan.com/ /
- Han sido merecedores de

reconocimientos nacionales e internacionales como el Premio Europeo de Microfinanzas 2017 y la medalla al Mérito Cooperativo que otorga la Cámara de Diputados de México en el año 2014.

- Esta unión incorpora a 8 cooperativas regionales $y$ tres as ociaciones civiles. actualmente la organización agrupa a 34,000 fa milias, la gran mayoría de ellos pertenecientes a los grupos or iginarios nahuas y tutunakus. La población de socios se conforma de 410 cooperativas locales pertenecientes 26 municipios de la sierra nororiental del estado de Puebla.

https://www.youtube.com/watch?v= OpNIfrP1_Lk 


\section{Casos de Empresas de Economía Social Multinacionales}




\section{Arla}

\section{Arla Foods}

Arla Foods es una cooperativa láctea multinacional nacida en 2001 de la fusión de la danesa Danish MD Foods y la sueca Swedish Arla.

La cooperativa es propiedad de 11.300 ganaderos repartidos entre Dinamarca, Suecia, el Reino Unido, Alemania, Bélgica, Luxemburgo y los Países Bajos.

https://www.arla.com/
- Arla Foods opera como un grupo multinacional que emplea a cerca de 19.000 personas en todo el mundo. Controla filiales productivas en 12 países (Estados Unidos, China, Canadá, Argentina, Brasil, Reino Unido, Dinamarca, Alemania, Polonia, Suecia, Finlandia y Arabia Saudí) y dispone de oficinas de ventas en 30 países en todos los continentes. Además, sus productos se venden en más de 100 países.

\section{Cifras 2017}

- Producción: 13.900 millones de Kg. de leche

- Facturación: 10.300 millones de euros

- Beneficios: 120 millones de euros

- Empleo: 18.973 trabajadores

- https://www.youtube.com/watch? $\mathrm{v}=\mathrm{vUlfERRabDg}$ (corporate film) 


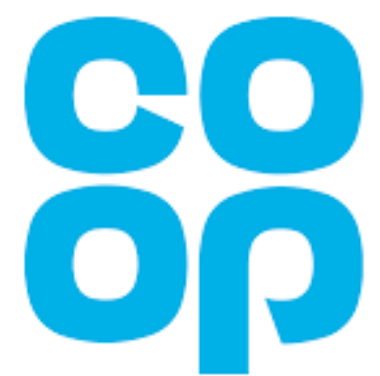

\section{Co-op}

Co-op, es una de las cooperativas de consumo más grandes del mundo, propiedad de millones de socios. Es el quinto minorista de alimentos en Reino Unido con más de 2500 tiendas locales de pequeño y mediano tamaño. También es el primer proveedor de servicios funerarios de Reino Unido, mientras continúan creciendo sus servicios legales y de seguros.

Desde 1844, ha tenido un claro compromiso social. La filosofía de esta cooperativa basa su existencia en la creación de valor en las comunidades en las que comercia; consideran que es que cuanto más éxito tengan, más poder podrán devolver a sus socios y a su comunidad. Nacen y trabajan para satisfacer las necesidades de sus socios y defender los proyectos e ideas en las que estos creen.

\section{Negocios}

- Comercio minorista de alimentos

- Seguros

- Servicios funerarios

- Servicios legales

- Planificación de vida

\section{Datos básicos (2017)}

- $\quad \mathrm{N}^{\circ}$ de supermercados: 2532

- $\quad N^{\circ}$ de funerarias: 1079

- Socios activos: 4.6 millones

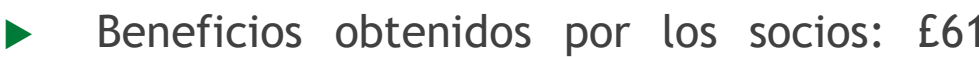
millones ( $5 \%$ recompensa para el socio)

- Beneficios obtenidos para la comunidad: £13 millones (1\% recompensa para la comunidad)

- Beneficios antes de impuestos: $€ 72$ millones

- Ingresos totales: $£ 9.5$ billones

https://www.co-operative.coop 
- Mondragón es uno de los principales grupos empresariales españoles, con cobertura nacional y amplia expansión internacional. Sus organizaciones operan en todo el mundo y desarrollan su actividad en el sector industrial, en el financiero, en el de la distribución y en el ámbito del conocimiento y la educación.

\section{Mondragón}

La Corporación Mondragón es una federación formada por 266 organizaciones (98 cooperativas, 143 filiales, 7 fundaciones, 1 mutua, 10 entidades de cobertura y 7 empresas de servicios internacionales). Sus orígenes se remontan a 1956 con la creación de talleres Ulgor, siendo José María Arizmendiarrieta el inspirador de la experiencia cooperativa.

https://www.mondragoncorporation.com/
La naturaleza como grupo integrado por cooperativas autónomas e independientes ofrece una alternativa exitosa en cuanto a organización participativa, solidaridad empresarial y compromiso social.

\section{Cifras 2017}

- Ingresos: 11.936 millones de euros

- Empleo: 80.818 personas

- I+D: 15 centros de I+D y más de 1.000 trabajadores

- Presencia internacional en 32 países

- https://www.youtube.com/watch?v=6R90 Y21C_L4 Inglés

- https://www.youtube.com/wateh?v=ULqn UFOvsic Español 


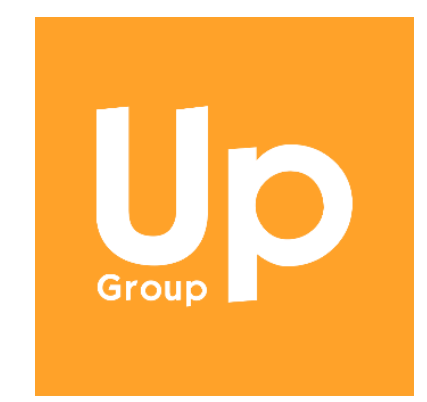

\section{Grupo UP}

El Grupo UP es un grupo empresarial especializado en soluciones empresariales y beneficios sociales para empleados. La empresa matriz, con sede en Francia, se estructura como una cooperativa propiedad de 664 trabajadores, siendo la segunda cooperativa más grande de Francia en términos de facturación y número de socios. Sus orígenes se encuentran en la creación de «Chèque Coopératif pour la Restaurationen» en 1964.

https://www.up.coop/en.html
- Como organización multinacional, el Grupo UP opera en 19 países y da empleo a cerca de 3.400 personas en todo el mundo. El $70 \%$ de la actividad productiva y el $60 \%$ del empleo total del grupo se concentran fuera de su país de origen, Francia. Un aspecto particularmente relevante en el caso del Grupo UP es que su Plan Estratégico de 2018 contempla la difusión global del modelo cooperativo en todas sus filiales. De momento, tres filiales francesas ya han sido integradas en la matriz cooperativa UP, convirtiéndose 250 trabajadores en nuevos socios cooperativistas.

\section{Cifras 2016}

- Facturación: 445 millones de euros

- Empleo: 3.396 trabajadores en todo el mundo

- 1,3 millones de clientes y 24,5 millones de beneficiarios

Presencia internacional en 19 países

- https://www.youtube.com/watch?v=15WGSg AElow Inglés 


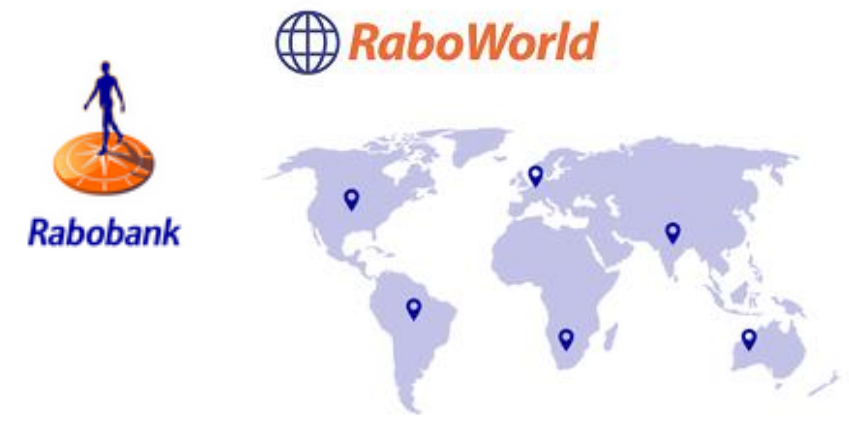

\section{Rabobank}

Rabobank es un proveedor internacional de servicios financieros, especializado en el sector agroalimentario. Su matriz está establecida en Utrecht (Holanda), donde Rabobank se estructura como una cooperativa propiedad de sus clientes socios. Su origen más directo se encuentra en Rabobank Nederland, fundado en 1972.

\section{https://www.rabobank.com/en/h ome/index.html}

- Rabobank está formado por 102 bancos locales holandeses propiedad de 1,9 millones de socios, además de alrededor de 380 filiales que permiten ofrecer sus servicios financieros en 38 países. Las principales actividades de Rabobank se centran en la banca minorista y mayorista, la banca privada, los servicios de alquiler financiero (leasing) y los negocios de bienes inmuebles. La actividad económica y social de Rabobank contribuye de manera directa a la consecución de los objetivos de desarrollo sostenible de Naciones Unidas.

\section{Cifras 2017}

- Empleo: 43,810 personas en todo el mundo

- Beneficios: 2.700 millones de euros

- Oficinas: 835 oficinas (389 en Holanda y 446 en el extranjero)

- https://www.youtube.com/watch?y=Rla 8b6JaZ8U Inglés 
Bibliografía 
- Atadi: http://www.atadi.es/

- Arla Foods: https://www.arla.com/

- Asociación La Traviesa: https://www.economiasolidaria.org/entidades/asociacion-la-traviesa

- Caja Rural de Teruel: https://www.ruralvia.com/teruel/

- Central de Cooperativas El Ceibo: http://www.elceibo.com/

- Cereales Teruel: http://cerealesteruel.com/

- Co-op: https://www.co-operative.coop

- Coop57: https://coop57.coop

- Cooperativa los Monegros: https://www.cooperativalosmonegros.es/

- Cooperativa integral agrícola mujeres 4pinos: http://www.mujerescuatropinos.com/

- Fundación Adunare: http://www.adunare.org/

- Fundación Espriú: www.fundacionespriu.coop/

- Fundación Rey Ardid: https: //reyardid.org/

- Fundación Picarral: https: //fundacionpicarral.org/

- Grupo Arcoiris: http://www.grupoarcoiris.com/

- Grupo Ars Alendi: http://alendi.es/

- Grupo Pastores: https://www.grupopastores.coop/

- Grupo Up: https://www.up.coop/en.html

- La Borda Cooperativa d'habitatge en cessió d'ús: http://www.laborda.coop/

- Mapiser: https://mapiser.com/

- Meri Henua Coop: https://cooperativas.emol.com/noticias/meri-henua-cooperativa-rapanui/

- MESCoop Aragón, Mercado Social: https://mercadosocialaragon.net/

- Mondragón: https://www.mondragon-corporation.com/

- Musethica: https://musethica.org/es/

- Rabobank: https://www.rabobank.com/en/home/index.html

- Red Social Koopera: http://koopera.org/

- San Juan Bautista Sociedad Cooperativa Limitada: http://www.coopfuendejalon.com/

- Smart Ibérica de Impulso Empresarial: https://smart-ib.coop/

- Som Energia: https://www.somenergia.coop

- Tasubinsa: http://www.tasubinsa.com/

- Tiebel: http://tiebelcooperativa.com

- Unión Cooperativas Tosepan: http://www.tosepan.com 